УДК 65.011 .56

DOI $10.21661 / \mathrm{r}-470776$

\title{
М.К. Кузнецов-Сербский
}

\section{ИССЛЕДОВАНИЕ ВОЗМОЖНОСТЕЙ АВТОМАТИЗАЦИИ ПРОЦЕССА ПРИЁМА СТУДЕНТОВ}

Аннотация: данную статью автор посвятил исследованию возможностей автоматизации процесса приёма студентов., так как деятельность любого высшего учебного заведения напрямую зависит от количества и качества набираемого контингента. Автор отмечает, что процесс подачи документов на выбранную специальность зачастую связан со множеством неудобств.

Ключевые слова: исследование, автоматизация процесса, приём студентов.

\section{M.K. Kuznecov-Serbskij}

\section{STUDYING THE POSSIBILITIES OF AUTOMATION OF THE STUDENT'S ADMISSION PROCESS}

Abstract: this article is devoted to the study of the possibilities of automation of the student's admission process, since the activity of any higher educational institution directly depends on the number and quality of the recruited contingent. The author notes that submission process for the chosen profession is associated with a number of inconveniences.

Keywords: research, process automation, admission of students.

Введение

Деятельность любого высшего учебного заведения напрямую зависит от количества и качества набираемого контингента. Процесс подачи документов на выбранную специальность зачастую связан со множеством неудобств, таких как, например, трата драгоценного времени в очередях на поступление. Первой инстанцией, которую требуется пройти абитуриенту, является приёмная комиссия (ПК). Внедрение цифровых технологий именно на этом этапе позволит 
автоматизировать обращение документов. Это существенно сократит затрачиваемые человеческие ресурсы и время необходимое для поступления на специальность.

Компьютеризация процесса позволит приёмной комиссии и руководству вуза своевременно обмениваться информацией и проводить зачисление в режиме реального времени, а также предоставит абитуриенту качественно новые возможности в выборе направления. Хранение данных в цифровом виде даёт возможность накапливать и обрабатывать аналитическую и статистическую информацию, для совершенствования и оптимизации последующих приёмных мероприятий.

\section{Процедура приёма документов}

Для многих ВУЗов процедура приёма, довольно-таки, стандартна, однако везде присутствуют свои особенности, которые необходимо учитывать для каждого в частности.

При подаче заявления в приёмную комиссию абитуриент должен предоставить определённый заранее перечень документов, среди них документ, удостоверяющий личность (в большинстве случаев это паспорт), аттестат о среднем полном (или о средне-профессиональном) образовании, результаты ЕГЭ (или же внутренних экзаменов вуза) шесть фотокарточек 3х4.

Следующим шагом поступающего является составление заявления, в котором должен сообщить о себе некоторую информацию и указать специальность, на которую претендует поступить. На этом этапе целесообразно принимать во внимание личные достижения абитуриента и формировать отдельные списки поступающих по целевому набору, чтобы заблаговременно отделять их от основной массы студентов.

В результате кампании по слиянию ВУЗов, приёмные комиссии многих университетов и институтов были расположены в разных частях города. Ключевая особенность состоит в том, что они расположены территориально далеко друг от друга. Часто обучение на конкретном направлении предоставляется исключительно на одной из платформ, и подача документов на определённые 
специальности может проводиться только в том корпусе, где эта специальность преподаётся. Это представляет из себя определённую трудность для абитуриентов. Соответственно необходимо предоставить поступающим возможность подавать заявления и документы на выбранную специальность в любом подразделении ВУЗа.

В зависимости от выбранных направлений абитуриент должен предоставить перечень сданных экзаменов, необходимых для поступления. Если же таковых не имеется, поступающий обязан сдать внутренние экзамены ВУЗа.

Сами внутренние экзамены могу сдаваться посменно в несколько потоков. Группы студентов, сдающих определённый предмет, должны формироваться в соответствии с пропускной способностью аудиторий и возможностями профессорско-преподавательского состава. При необходимости должно быть составлено расписание приёма экзаменов по дням. Результаты полученные в ходе прохождения испытаний должны также учитываться в электронной ведомости наравне с баллами ЕГЭ.

Моделирование процесса зачисления абитуриентов

Благодаря компьютерному и программному моделированию различных сфер человеческой деятельности можно с большой долей вероятности прогнозировать итоговый результат и избежать большого количества ошибок. ЭВМ позволяет воочию увидеть рабочую модель интересующих нас процессов и отразить основные механизмы их работы. Для осуществления такого вида исследований применяются разного рода среды разработки и системы автоматического проектирования (САПР).

Рассматриваемый нами процесс, как и многие представляет из себя разветвлённый алгоритм со множеством пунктов. Что бы представить нашу модель наиболее наглядно, для описания применим алгоритмический язык ДРАКОН. Этот язык представляет собой отечественную разработку в области визуального моделирования и применяется в настоящее время для программирования космических спутников всех типов и автоматизации многих систем космических кораблей. Правила языка ДРАКОН по созданию диаграмм разрабатывались с 
учётом требований эргономики, то есть изначально оптимизированы для восприятия алгоритмов человеком с использованием технологий компьютерной графики. Эти и другие особенности дают языку сильное преимущество над классическими блок-схемами. Хотя блок-схемы порою действительно улучшают понимаемость программ, однако это происходит не всегда, причем степень улучшения невелика. Кроме того, есть немало случаев, когда неудачно выполненные блок- схемы запутывают дело и затрудняют понимание. В отличие от них дракон-схемы удовлетворяют критерию сверхвысокой понимаемости. 

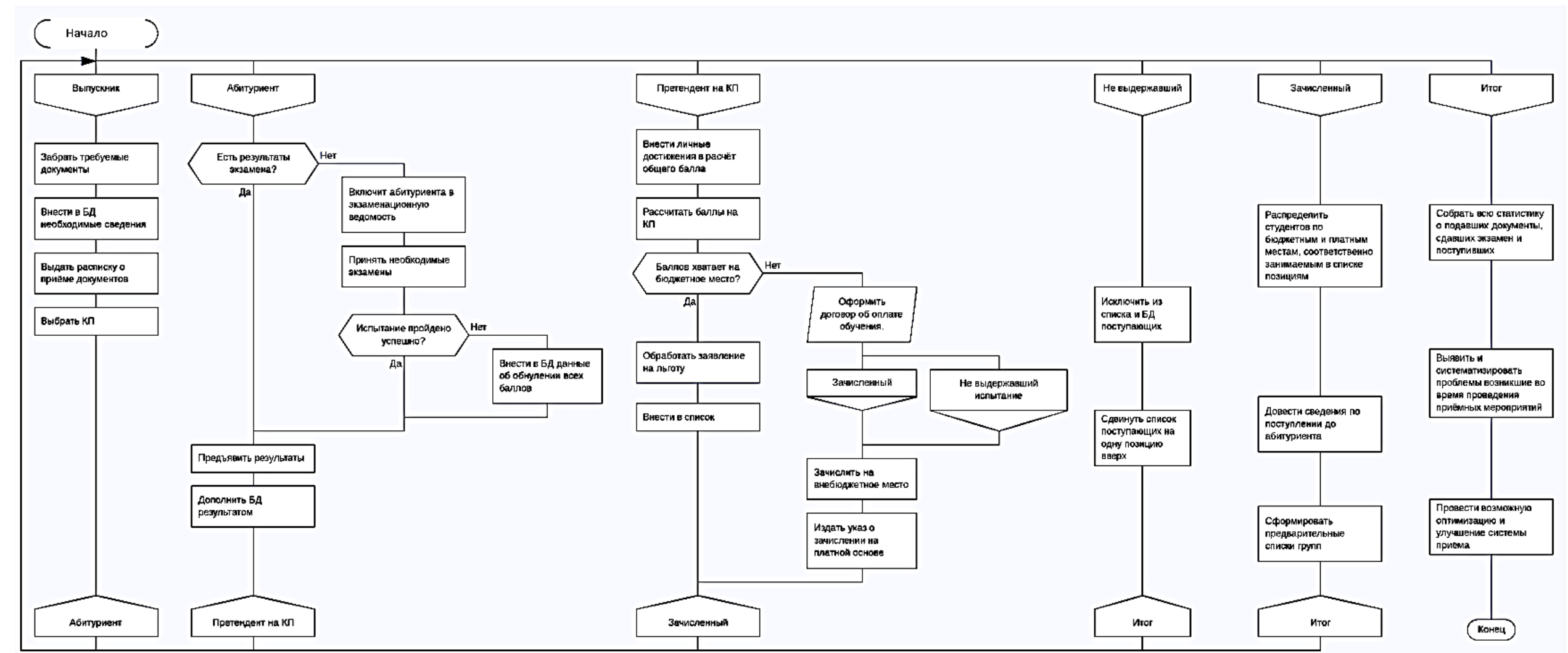

Рис. 1 
На рисунке 1 представлен алгоритм возможной модели автоматизации работы приёмной комиссии. Для простоты понимания весь процесс разбит на отдельные части - «ветви» алгоритма, связь между которыми может осуществляться, как классически (линиями, их соединяющими), так и с помощью адресации - особенной иконой, характеризующей алгоритмический язык ДРАКОН. Представленный подход позволяет убрать все линии, что на больших чертежах освобождает рабочее пространство и существенно упрощает аналитическое восприятие рассматриваемого алгоритма. *

Следует также обратить внимание и на техническую реализацию процесса. Взаимодействие с системой происходит с помощью системы терминалов, которые, в свою очередь, топологически представляют из себя звезду. Такой подход позволит обеспечить быстрый доступ к системе большому числу пользователей с максимальной эффективностью. Сначала все данные вводятся в терминал (рисунок 2) поступающими самостоятельно, или с помощью операторов. После внесения данных они автоматически занимают соответствующую позицию в БД, а выпускник получает на руки распечатку расписки, подтверждающей успешный приём документов. Теперь выпускник попадает в категорию абитуриент. Несмотря на то, что внесённые документы принимаются комиссией, участие в конкурсе без наличия результатов экзаменов недопустимо.

Терминалы предназначены для ввода данных, дальше производится передача информации на сервер, где она хранится в базе данных. Доступом к этой базе обладает приёмная комиссия и ректорат высшего учебного заведения, что позволяет в любой момент времени проконтролировать заполняемость бюджетных мест и мест обучения на коммерческой основе.

После записи в очередной ячейки БД, сервер отвечает на запрос пользователя. Этот ответ обрабатывается терминалом, и если сбоев в работе не выявлено, даётся команда на устройство предназначенное для вывода текстовой информации. Получаемый на руки документ является распиской и считается документом подтверждающим успешное принятие документов. При отсутствии результата 
экзамена экзаменационная ведомость автоматически пополняется очередным конкурсантом.

Предполагается, что если необходимо пройти внутренние испытания, то поступающий должен подать заявление и документы не позднее, чем за один день до проведения первого экзамена, что бы у ПК была возможность занести его в экзаменационную ведомость.

После внесения баллов в таблицу БД, они автоматически пересчитываются в конечный результат с учётом личных достижений. Вследствие этого формируются списки поступающих на КП, упорядоченные по убыванию результирующей суммы баллов. По результатам работы системы возможно зачисление абитуриента только на одну конкурсную позицию.

Абитуриент имеет возможность отозвать свой запрос на определённое направление по причине поступления на бюджетное место на другую специальность, другого ВУЗа или иной причине. Для этого составляется отдельная форма в одном из терминалов на отзыв заявления. В этом случае первое заявление аннулируется и все данные о поступавшем удаляются из общей базы системы. В этом случае компьютер очищает, занимаемую ранее поступавшем строку в базе данных.

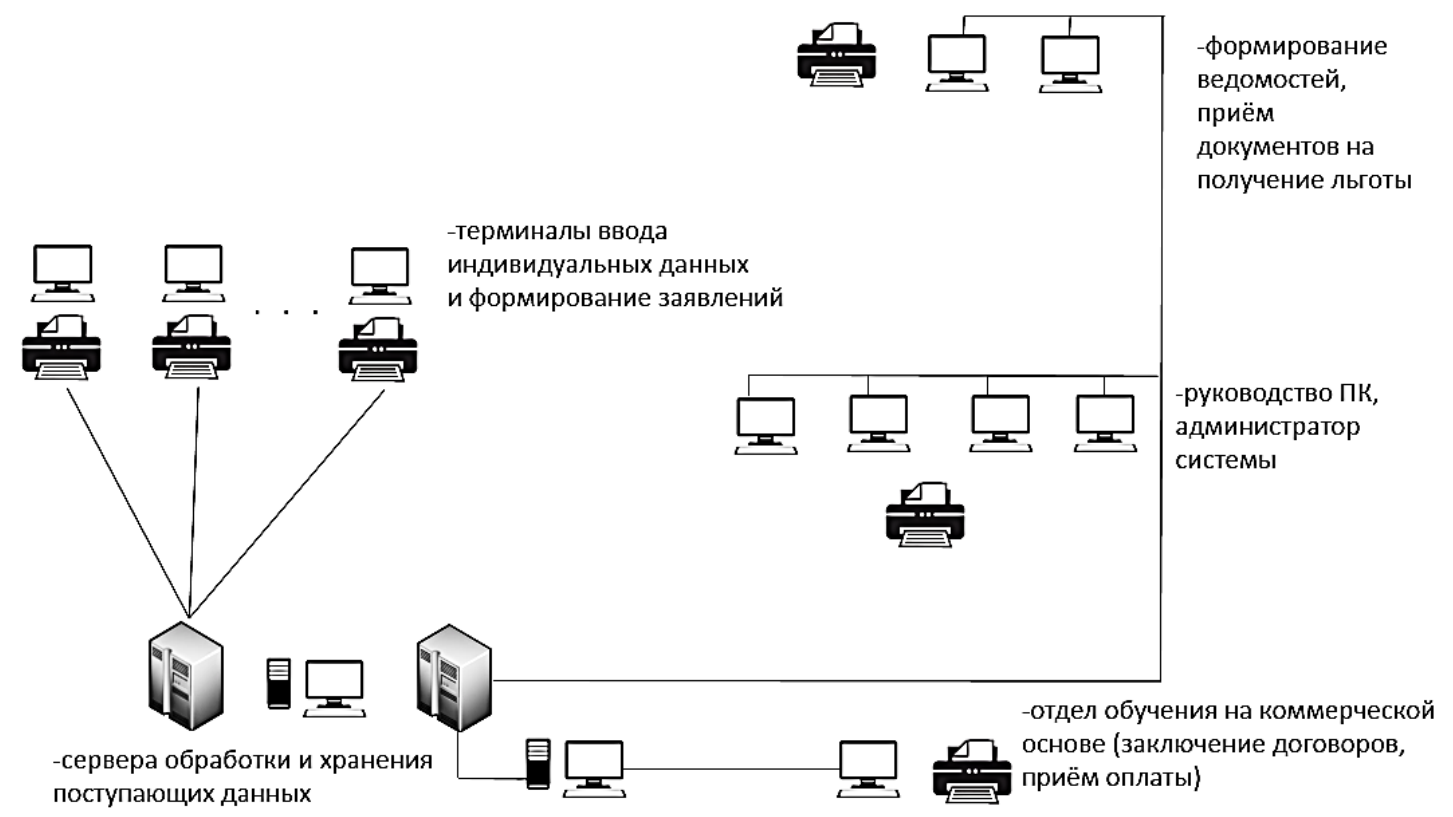

Рис. 2 
Следующим после заполнения бюджетных мест идёт распределение внеплановых мест между заключившими договор. Абитуриенты прошедшие на обучение на коммерческой основе направляются на оплату обучения в отдел договорных отношений. В дальнейшем их внесут в отдельный список поступивших. Согласно этому списку и будут распределены места предназначенные для обучающихся на платной основе.

\section{Заключение}

В заключении хотелось бы отметить, что такой подход к автоматизации работы приёмной комиссии не только ускоряет процесс приёма выпускников, но и даёт возможность существенно сократить количество занятого персонала, что в свою очередь позволяет ВУЗу экономить немалые средства. Хранимая информация может быть использована в дальнейших мероприятиях, проводимых ВУЗом, анализе и систематизации статистических данных. Более того особенности языка ДРАКОН существенно упрощают реализацию и понимание алгоритмической составляющей системы и ремонт возможных неисправностей.

\section{Сиисок литературы}

1. Основы автоматического управления. / Под ред. А.А Воронова. - М.: Высшая школа, 1986.

2. Левитин А.В. Алгоритмы: введение в разработку и анализ. - М.: Вильямс, 2006. $-576 \mathrm{c}$.

3. Лэнгсам Й. Структуры данных для персональных ЭВМ / Й. Лэнгсам, М. Оген-стайн, А. Тененбаум. - М.: Мир, 1989. - 567 с.

4. Макконнелл Дж. Основы современных алгоритмов. - 2-е изд., доп. - М.: Техносфера, 2004. - 368 c.

5. Паронджанов. В.Д. Как улучшить работу ума: Алгоритмы без программистов - это очень просто! - М.: Дело, 2001. - 360 с.

6. Погромская Т.А. Модель процесса приема абитуриентов в вуз // МСиМ. 2003. - №2 (12). - C. 155-160.

7. Свами М. Графы, сети и алгоритмы / М. Свами, К. Тхуласираман. - М.: Мир, 1984. - 455 с. 
8. Цилькер Б.Я. Организация ЭВМ и систем: Учебник для вузов / Б.Я. Цилькер, С.А. Орлов. - 2-е изд. - СПб.: Питер, 2011. - 688 с.

\section{References}

1. (1986). Osnovy avtomaticheskogo upravleniia. M.: Vysshaia shkola.

2. Levitin, A. V. (2006). Algoritmy., 576. M.: Vil'iams.

3. Lengsam, I., \& Tenenbaum, A. (1989). Struktury dannykh dlia personal'nykh EVM., 567. M.: Mir.

4. Makkonnell, D. (2004). Osnovy sovremennykh algoritmov., 368. M.: Tekhnosfera.

5. (2001). Parondzhanov. V.D. Kak uluchshit' rabotu uma: Algoritmy bez programmistov - eto ochen' prosto!., 360. M.: Delo.

6. Pogromskaia, T. A. (2003). Model' protsessa priema abiturientov v vuz. MSiM, 2 (12), 155-160.

7. Svami, M., \& Tkhulasiraman, K. (1984). Grafy, seti i algoritmy., 455. M.: Mir.

8. Tsil'ker, B. Ia., \& Orlov, S. A. (2011). Organizatsiia EVM i sistem: Uchebnik dlia vuzov., 688. SPb.: Piter.

Кузнецов-Сербский Марк Константинович - студент ФГБОУ ВО «Московский технологический университет», Россия, Москва.

Kuznecov-Serbskij Mark Konstantinovich - student at the Moscow Technological University, Russia, Moscow. 